\title{
BM] Global Health Effects of refresher training on the use of manual vacuum aspiration in the treatment of incomplete abortions: a quasi-experimental study in Malawi
}

\author{
Maria Lisa Odland, ${ }^{1}$ Gladys Membe-Gadama, ${ }^{2}$ Ursula Kafulafula, ${ }^{3}$ \\ Geir Wenberg Jacobsen, ${ }^{1}$ Jon Øyvind Odland, ${ }^{1}$ Elisabeth Darj ${ }^{1}$
}

To cite: $O d l a n d ~ M L$,

Membe-Gadama G Kafulafula U, et al. Effects of refresher training on the use of manual vacuum aspiration in the treatment of incomplete abortions: a quasi-experimental study in Malawi. BMJ Glob Health 2018;3:e000823. doi:10.1136/ bmjgh-2018-000823

Handling editor Seye Abimbola

Received 13 March 2018 Revised 29 June 2018 Accepted 2 July 2018

Check for updates

(c) Author(s) (or their employer(s)) 2018. Re-use permitted under CC BY-NC. No commercial re-use. See rights and permissions. Published by BMJ.

${ }^{1}$ Department of Public Health and Nursing, Norwegian University of Science and Technology, Trondheim, Norway ${ }^{2}$ Queen Elizabeth Central Hospital, Blantyre, Southern Region, Malawi

${ }^{3}$ Kamuzu College of Nursing, University of Malawi, Blantyre, Southern Region, Malawi

Correspondence to Dr Maria Lisa Odland; maria...odland@ntnu.no

\section{ABSTRACT}

Introduction The maternal mortality ratio is decreasing globally, although it remains high in Malawi. Unsafe abortion is a major cause and treatment of complications after abortion is a big burden on the health system. Even though manual vacuum aspiration (MVA) is the recommended surgical treatment of incomplete abortions in the first trimester, many hospitals in Malawi continue to use sharp curettage. It is known to have more complications and is more expensive in the long run. The purpose of this study was to determine the effectiveness of a structured MVA training programme in the treatment of incomplete abortions in Malawi.

Methods A quasi-experimental before-and-after study design was employed in an MVA training programme for health personnel at three hospitals in Southern Malawi. A total of 53 health personnel at the Queen Elizabeth Central Hospital and the district hospitals of Chikwawa and Chiradzulu (intervention hospitals) were trained in the use of MVA. Kamuzu Central Hospital in Lilongwe and the Thyolo District Hospital served as control institutions. Medical files for all women treated for an incomplete abortion at the study hospitals were reviewed before and after the intervention. Information on demographic and obstetric data and the type of treatment was collected. Results There was a significant increase in the use of MVA from $7.8 \%$ (95\% Cl 5.8 to 10.3$)$ to $29.1 \%(95 \% \mathrm{Cl}$ 25.9 to 32.5$) 1$ year after the intervention. In comparison, we found a mere $3 \%$ increase in the control hospitals. Conclusions By providing a refresher training programme to health personnel who treat women with incomplete abortions, it was possible to increase the use of MVA as recommended in the Malawi national guidelines.

\section{INTRODUCTION}

Malawi is a small country in southeastern Africa with about 18 million inhabitants. ${ }^{1}$ The Malawian health system is impoverished and the maternal mortality ratio is high with 439 deaths per 100000 live births. ${ }^{2-5}$ The total fertility rate is 4.4 per woman, ${ }^{5}$ while the adolescent birth rate is 141 per 1000 indicating a high birth rate. ${ }^{1}$

\section{Key questions}

What is already known?

- Incomplete abortion is a common complication after a miscarriage and uterine evacuation is needed to avoid further complications such as haemorrhage, sepsis and even death.

- Even though manual vacuum aspiration (MVA) is the recommended surgical treatment for incomplete abortions, many hospitals in Malawi continue to use sharp curettage.

\section{What are the new findings?}

- A simple MVA training intervention was instrumental to increase the use of the procedure in the treatment of incomplete abortions in Malawi.

- While previous interventions from other countries often involve donations of equipment, our study shows what can be achieved on a smaller scale using local resources.

What do the new findings imply?

- The use of MVA in the treatment of incomplete abortions in Malawi is still lower than recommended, but may be improved by providing periodic MVA training for health personnel in tandem with the provision of equipment.

Globally, unsafe abortion is one of the top five causes of maternal mortality ${ }^{6-8}$ and is estimated to be the cause of $6-30 \%$ of maternal deaths in Malawi. ${ }^{7-9}$ Even though induced abortion is only legal to save a woman's life, ${ }^{7}$ it is estimated that around 140000 induced abortions were performed in $2015 .^{10}$ Given this restrictive abortion law, most of them were likely clandestine and contributed to the high maternal mortality. There are ongoing discussions on how to modify the law; however, no change has been made so far. ${ }^{11}$ In the meantime, other measures are required to reduce the burden of unsafe abortions. 
Malawi has a high treatment rate for abortion complications, specifically 10.2 per 1000 women aged $15-44$, and thus, almost 19000 women were treated for such complications in 2009. ${ }^{12}$ An incomplete abortion with retained products of conception in the uterus may lead to haemorrhage, sepsis or even death as a worst-case scenario. ${ }^{13}$ In order to avoid such complications, surgical or medical uterine evacuation may well be necessary. In Malawi, medical treatment is used infrequently and most incomplete abortions are treated surgically. ${ }^{14} \mathrm{~A}$ fear of misuse of misoprostol to induce abortions could be one of the reasons most incomplete abortions in Malawi are treated surgically. Another concern is that patients can be lost to follow-up and subsequently need attention because of serious septic abortions. Stock depletion of medicines is also a common problem in Malawi, and therefore we chose to focus on surgical treatment and manual vacuum aspiration (MVA) in this study.

Surgical treatment of incomplete abortions employs traditional dilatation and curettage (D\&C) or vacuum aspiration. In line with recommendations from the WHO, MVA is the recommended surgical treatment for incomplete abortions in the first trimester in Malawi. ${ }^{1516}$ This method is cheaper, safer and has fewer complications such as haemorrhage and uterine perforation. ${ }^{17} 18$ Additionally, MVA can be performed under local anaesthetics, in areas without electricity and can be carried out by nurses/midwives. ${ }^{19}$ These are important factors when resources and health personnel are limited.

A previous study conducted in Southern Malawi in 2012 showed an annual decrease in the use of MVA, and only $4.9 \%$ of the hospitalised cases were treated with MVA. ${ }^{14}$ Suggested reasons for this were insufficient training, shortage of staff and inadequate equipment. ${ }^{20}$ Our overall objective was to improve post-abortion care in Malawi. Our aim was to increase the use of MVA by training health personnel at three Malawian public hospitals.

\section{METHODS \\ Study design}

We conducted a quasi-experimental study with a beforeand-after design. The intervention was a formalised training programme directed at MVA as the preferred procedure for treatment of incomplete abortions. Prevalence data for both MVA and D\&C were collected before and after the intervention.

\section{Study setting}

Our selection of study hospitals was opportunistic as we used two hospitals which had been included in a previous study, namely Queen Elizabeth Central Hospital (QECH) and the Chiradzulu District Hospital, and where we previously had found that the use of MVA was lower than recommended. ${ }^{14}$ The QECH in Blantyre is the main referral hospital in the southern part of the country (see map, figure 1). With about 11000 deliveries every year, many patients with incomplete abortions are also admitted. ${ }^{91}$ Together, the District Hospital in Chiradzulu (9500 births per year), a smaller district hospital in Chikwawa (3600 births annually) and the QECH were selected as intervention hospitals. In order to reduce influences such as concurrent campaigns or other initiatives, the Kamuzu Central Hospital and the Thyolo District Hospital were chosen as control hospitals (see map, figure 1). The former is a referral hospital, is one of the four central hospitals in Malawi and is located in the capital Lilongwe. The Thyolo District and the Chiradzulu District hospitals were of comparable size. The beforeand-after study design implies follow-up which was carried out 9-12 months after the intervention at all five sites.

\section{Data collection}

The MVA intervention training programme was conducted in April 2016 (see figure 2). The first set of data was collected during the 3 months preceding the intervention (January through March 2016) to obtain pre-intervention (baseline) information. Subsequently, the main data set was collected during the remainder (April-December) of 2016. The post-intervention (endline) information was collected during JanuaryMarch of 2017, and took place exactly 1 year after the intervention. Data from the control hospitals were obtained concomitantly.

All medical files for patients treated for incomplete abortions at the five study hospitals were reviewed. Information on demographics (age, marital status, education, occupation and religion), obstetric history (gravidity, parity and gestational age at admission) and type of treatment was collected. All the data were extracted and recorded by a team of three nurses who used the same protocol throughout the whole study period. They were led by a medical doctor who acted as the principal investigator (PI).

\section{Intervention}

The intervention targeted all pertinent health personnel treating patients with incomplete abortions, specifically nurses and clinical officers at the District Hospitals, and medical interns at the Central Hospitals. Each training session involved 12 participants who volunteered. At $\mathrm{QECH}$, the training was conducted as a part of the regular teaching sessions for interns. All relevant health workers were invited to participate. One training session took place in April 2016 at all three intervention hospitals. An extra training session was organised at QECH at the end of 2016 due to a new rotation of interns. The training was organised as a refresher course since basic knowledge about MVA had been acquired in their respective curricula. The session started with a theoretical component of 45 minutes that included background information on incomplete abortions, treatment options and details about the MVA procedure. A 10-step guide developed by Ipas was used. ${ }^{22}$ The material reviewed included: manual examination of the uterine size as a means to estimate the 


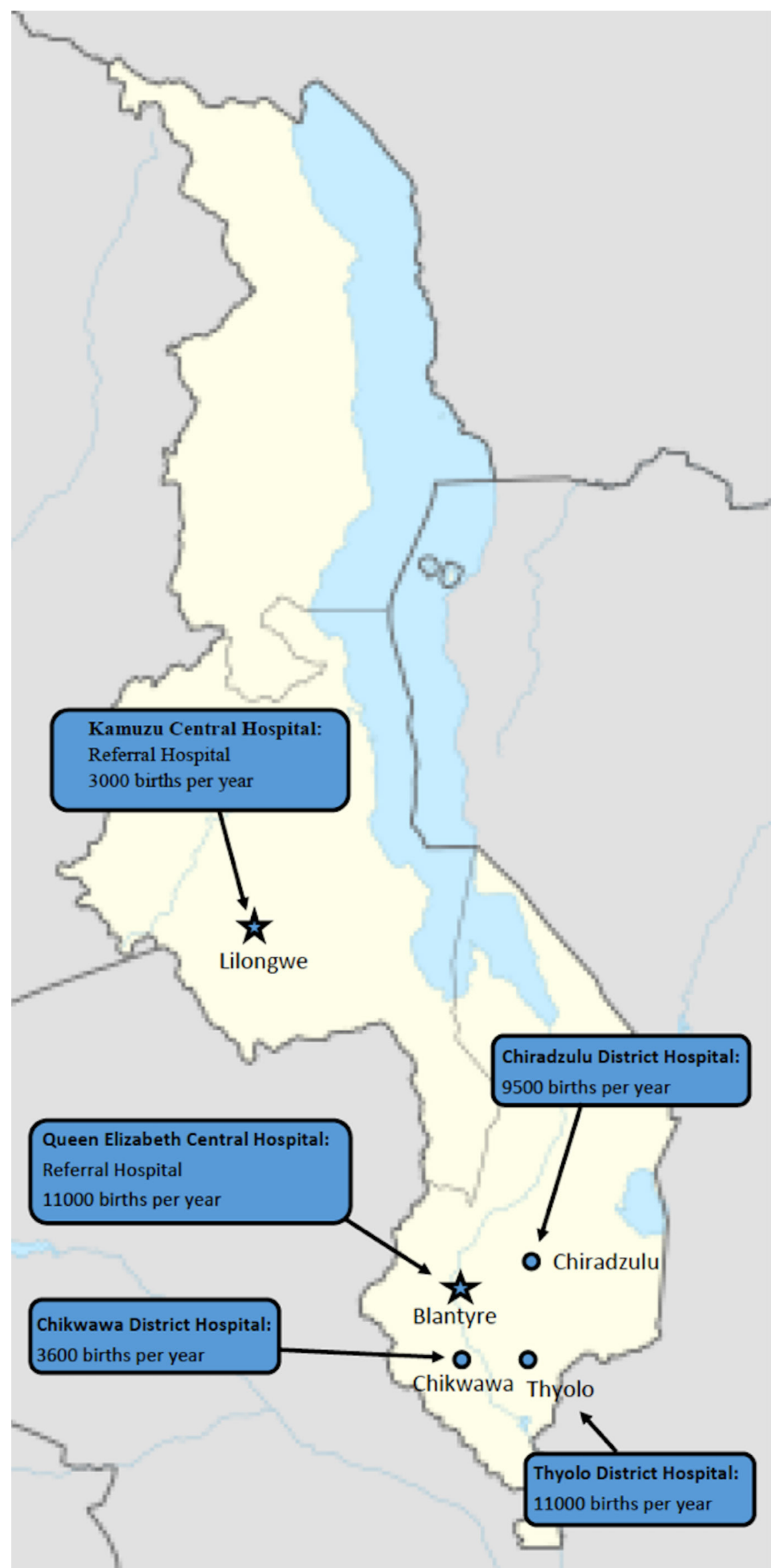

Figure 1 Location of study sites and number of deliveries. 
Intervention Hospitals

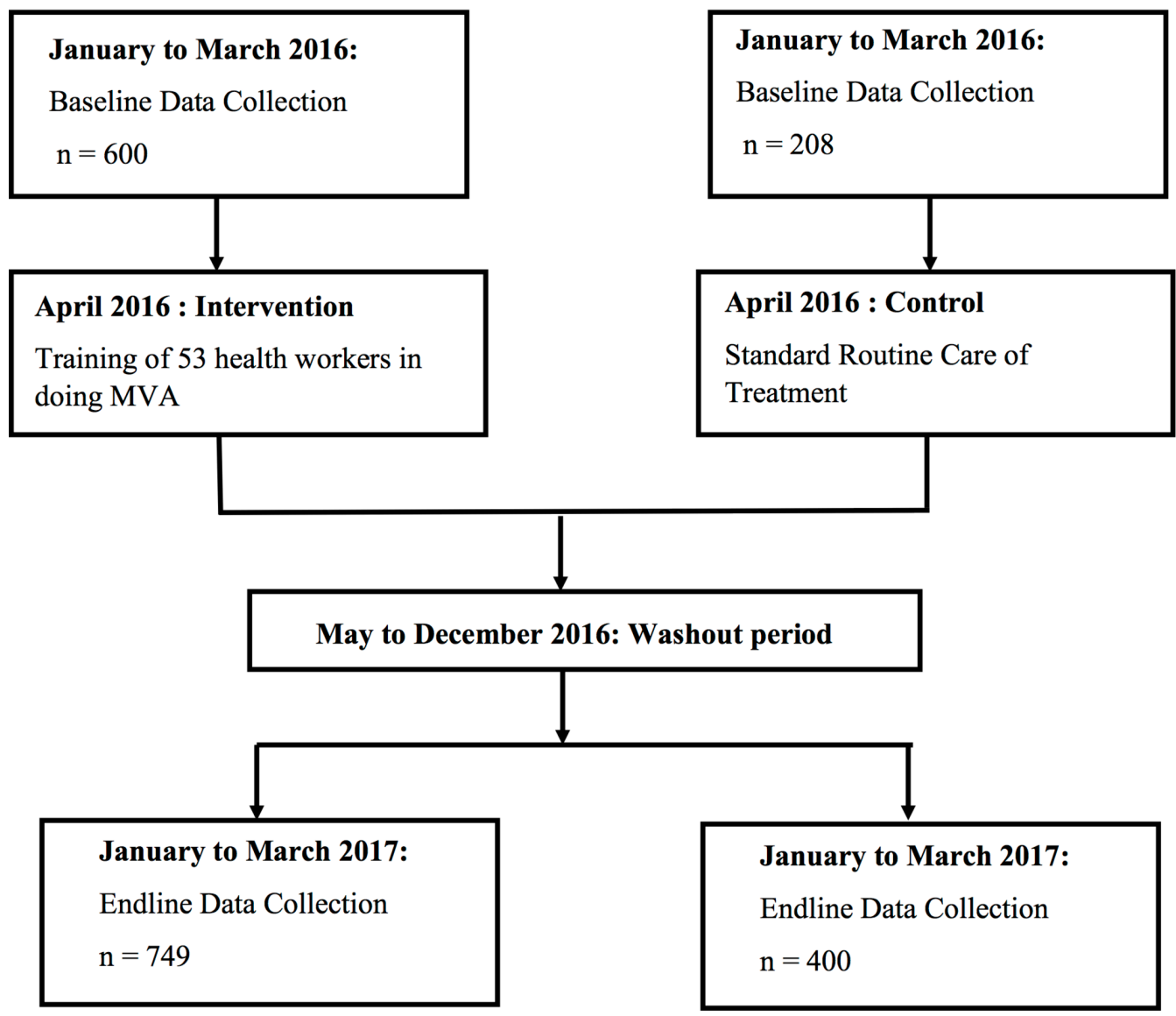

Figure 2 Phases of the data collection and numbers collected. MVA, manual vacuum aspiration.

gestational age and selecting the right size of the cannula; assembling and preparing the MVA kit; administration of pain relief and antiseptic preparations; insertion of speculum, forceps and of the cannula; suction of the uterine contents; signs that the uterus was empty; removal of the tenaculum forceps and the speculum carefully and examining the retained pregnancy products. ${ }^{22}$ Information on sterilisation of the equipment was also provided. After a short break, there was a 1-hour long practical part with training on pelvic models specially made for MVA training. There was no formal examination, but all the participants had to demonstrate that they managed the procedure on the pelvic models in a class setting. The training was conducted and supervised by the study PI and a local gynaecological consultant.

\section{Data analysis}

The main outcome measure was effectiveness. An overall increase in the use of MVA by $15 \%$ was considered clinically significant. Statistical analyses were conducted with a significance threshold of $\mathrm{p}<0.05$ using SPSS (V.22 SPSS, Chicago, Illinois, USA). Age is reported as mean with SD, while prevalence data are given as proportions with $95 \%$ CIs. The Chi Square statistics was used to compare the use of MVA before and after the intervention, and logistic regression to control any influence by confounding factors such as previous or current obstetric history and demographic data. Linear trend analysis was done to identify any significant trend in the study data.

\section{Ethics}

The health personnel who participated in the training were informed about the aim of the programme, and that their participation was voluntary. All patient data were collected retrospectively and were anonymised and replaced with a study-ID that could not be traced back to individual women.

\section{RESULTS}

Overall, we collected data from 4321 patients, of whom 3143 were treated for incomplete abortions at the intervention hospitals and 1178 at the control hospitals. As baseline data, 600 women who were consecutively treated at the intervention hospitals constituted the study group and were compared with 208 women at the control hospitals. Endline data were also obtained for 749 women at the intervention hospitals and 400 at the control institutions (see figure 2). The demographic characteristics and obstetric data for the women show that most were married, few had tertiary education and the most common religion was Christianity. The groups were similar in terms of sociodemographic 
Table 1 Characteristics of the women in the intervention and the control hospitals before and after the intervention*

\begin{tabular}{|c|c|c|c|c|}
\hline \multirow{2}{*}{$\begin{array}{l}\text { Characteristics of } \\
\text { women }(n=1857)\end{array}$} & \multicolumn{2}{|c|}{ Intervention hospitals } & \multicolumn{2}{|l|}{ Control hospitals } \\
\hline & Before $(n=600)$ & After $(n=749)$ & Before (n=208) & After $(n=400)$ \\
\hline Age (years) & $25.3(6.6)$ & $25.2(6.8)$ & $25.2(6.4)$ & $25.2(6.9)$ \\
\hline \multicolumn{5}{|l|}{ Marital status } \\
\hline Married & $84.1(75.8-90.5)$ & $82.2(74.5-88.3)$ & $91.0(85.2-95.1)$ & $84.5(78.7-89.2)$ \\
\hline Unmarried & $15.9(9.5-24.2)$ & $17.8(11.0-24.7)$ & $9.0(4.9-14.8)$ & 15.5 (10.8-21.3) \\
\hline \multicolumn{5}{|l|}{ Educational level } \\
\hline None & $6.3(2.1-14.0)$ & $1.2(0.0-6.5)$ & $12.4(1.6-38.3)$ & 0.0 \\
\hline Primary & $47.5(36.2-59.0)$ & $49.4(38.2-60.6)$ & $43.8(19.8-70.1)$ & $55.6(21.2-86.3)$ \\
\hline Secondary & $37.5(26.9-49.0)$ & $45.8(34.8-57.1)$ & $43.8(19.8-70.1)$ & $33.3(7.5-70.1)$ \\
\hline Tertiary & $8.7(3.6-17.2)$ & $3.6(0.8-10.2)$ & 0.0 & $11.1(0.3-48.2)$ \\
\hline \multicolumn{5}{|l|}{ Religion } \\
\hline Christian & $82.2(72.2-88.0)$ & 87.1 (81.2-91.6) & 86.5 (71.2-95.5) & $73.0(55.9-86.2)$ \\
\hline Islam & $10.5(6.1-16.5)$ & $7.8(4.4-12.8)$ & $5.4(0.7-18.2)$ & $5.4(0.7-18.2)$ \\
\hline Other & $7.3(3.7-12.6)$ & $5.1(2.3-9.4)$ & $8.1(1.7-21.9)$ & $21.6(9.8-38.2)$ \\
\hline \multicolumn{5}{|l|}{ Occupation } \\
\hline None & $45.7(33.7-58.1)$ & $35.0(26.5-44.4)$ & $33.3(18.0-51.8)$ & $38.9(23.1-54.8)$ \\
\hline Employed & $44.3(32.4-56.7)$ & $51.3(41.9-60.6)$ & $57.6(39.2-74.5)$ & $38.9(23.1-56.5)$ \\
\hline Student & $10.0(4.1-19.5)$ & $13.7(8.0-21.3)$ & $9.1(1.9-24.3)$ & $22.2(10.1-39.2)$ \\
\hline \multicolumn{5}{|l|}{ Pregnancy history } \\
\hline Primigravida & $29.5(25.3-34.0)$ & $33.8(30.2-37.6)$ & $22.6(15.8-30.6)$ & $33.2(26.9-39.9)$ \\
\hline Multigravida & $70.5(66.0-74.4)$ & $66.2(62.4-69.8)$ & $77.4(69.4-84.2)$ & $66.8(60.1-73.1)$ \\
\hline \multicolumn{5}{|l|}{ Gestational age } \\
\hline First trimester & 34.7 (30.6-39.1) & $36.2(32.7-39.9)$ & $38.2(31.0-45.8)$ & $36.6(30.9-42.6)$ \\
\hline Second trimester & $65.3(60.9-69.4)$ & $63.8(60.1-67.3)$ & $61.8(54.2-69.0)$ & $63.4(57.4-69.1)$ \\
\hline Weeks of amenorrhea & $12(4-28)$ & $12(1-26)$ & $12(4-27)$ & $12(3-27)$ \\
\hline
\end{tabular}

${ }^{*}$ Age is given as a mean (SD), amenorrhea as the median (range) in weeks and other characteristics as percentages (95\% Cls).

and reproductive characteristics (table 1). Potential confounding factors such as education, occupation and the number of previous pregnancies differed slightly before and after the intervention. We adjusted for these inequalities in the logistic regression models and observed no influence on the results.

There was a significant increase in the use of MVA from $7.8 \%$ (95\% CI 5.8 to 10.3) in January-March 2016 to $29.1 \%$ (95\% CI 25.9 to 32.5) in January-March 2017 (table 2). This gave a relative increase in the use of MVA of $21.3 \%$. Concurrently, there was a significant decrease in the use of D\&C from $83.7 \%$ (95\% CI 80.5 to 86.5 ) before the intervention to $69.2 \%$ (95\% CI 64.8 to 71.5 ) after its completion (figure 3). In the control hospitals, there was just minor $(3 \%)$ relative increase in the use of MVA. Overall, this gave a net intervention effect of $18.3 \%$.

The increase in MVA indicated in table 2 mainly took place at QECH. The largest proportion of patients were treated here, and following the intervention, MVA was used in almost $40 \%$ of the cases. For comparison, the use of medical treatment was negligible in all hospitals, and based on the endline data, it was offered to just $1.1 \%$ (95\% CI 0.5 to 2.1$)$ of the patients.

\section{DISCUSSION}

This short refresher training course in MVA was successful since the use of the procedure increased by $21.3 \%$ from baseline use before the training. In view of our findings, refresher training of the necessary skills can be instrumental in enhancing the use of MVA and thereby improve post-abortion care, and do so at a lower cost.

Table 2 The use of manual vacuum aspiration in the months before and after the intervention*

\begin{tabular}{lll}
\hline & $\begin{array}{l}\text { Intervention } \\
\text { group } \\
(\mathbf{n = 3 1 4 3 )}\end{array}$ & $\begin{array}{l}\text { Control group } \\
(\mathbf{n = 1 1 7 8})\end{array}$ \\
\hline Jan-March 2016 & $7.8(5.8-10.3)$ & $1.0(0.1-3.4)$ \\
\hline April-June 2016 & $12.0(9.5-15.0)$ & $1.1(0.1-4.0)$ \\
\hline July-Sep 2016 & $7.4(5.4-9.8)$ & $0.5(0.0-2.7)$ \\
\hline Oct-Dec 2016 & $10.9(8.6-3-6)$ & $1.4(0.4-3.5)$ \\
\hline Jan-March 2017 & $29.1(25.9-32.5) \dagger$ & $4.0(2.1-6.9) \ddagger$ \\
\hline
\end{tabular}

${ }^{*}$ Data are \% $(95 \% \mathrm{Cl})$.

$\dagger \mathrm{P}$ value for linear trend $<0.001$.

$\ddagger P$ value for linear trend $<0.05$. 


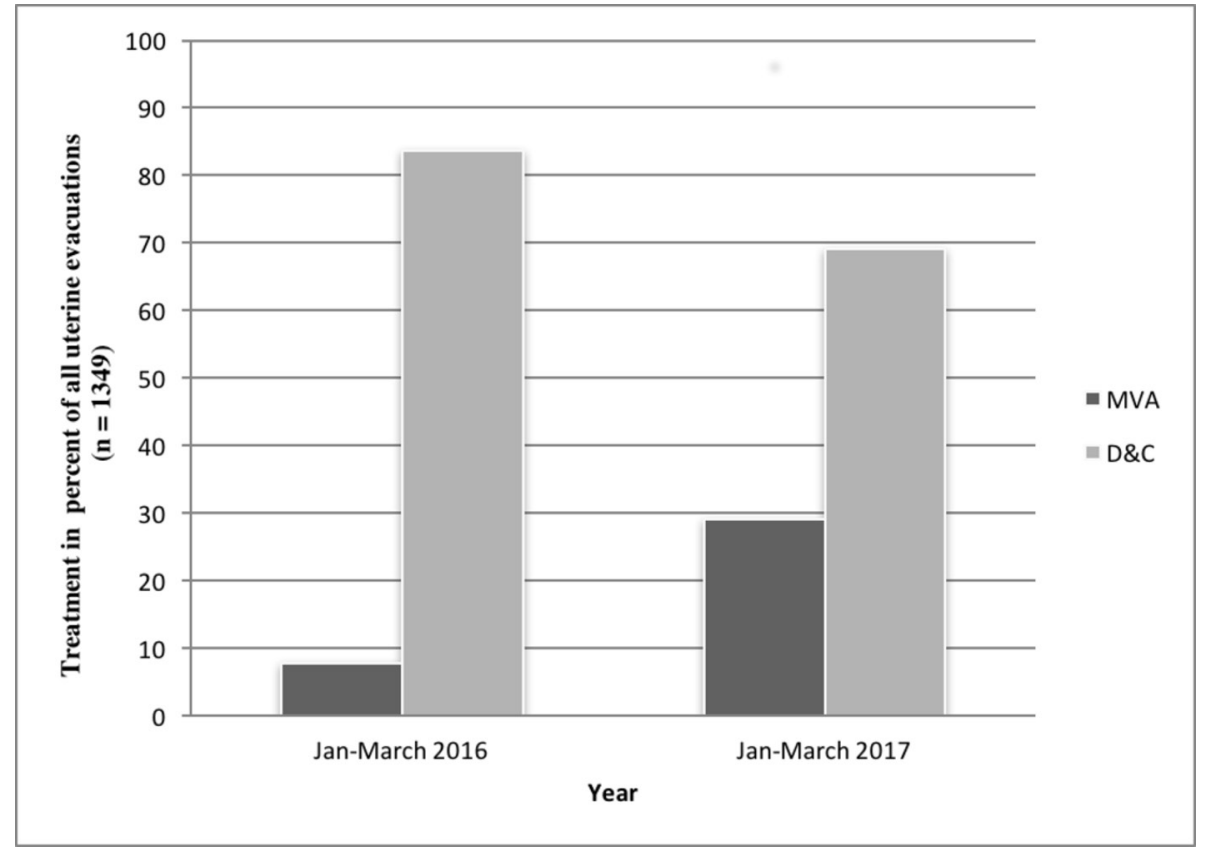

Figure 3 Difference in the proportion of incomplete abortions treated with manual vacuum aspiration (MVA) and dilatation and curettage (D\&C) before and after the intervention.

A strength of this study is that it was conducted in both referral and district hospitals that reflects the locations and size of hospitals elsewhere in Malawi. Consequently, our findings are likely to be representative for the country as a whole. The involvement of the two control hospitals where no MVA training programme was offered enhances the validity of our results by minimising the influence of other potential (unknown) confounders. We hold that our results indicate that the observed increase was a result of the training, and apparently, not by any other concurrent national initiatives.

The training was fairly short and basic with no engagement of true patients and yet we managed to get a significant increase in the use of MVA. Moreover, the training effort was intended as a refresher as all health personnel learn about MVA as a part of their basic training and thus were familiar with its use. Other factors such as lack of equipment and staff are other probable constraints that lead to reduced use of MVA and cannot be accounted for as pointed out by Cook et al who worked in the same study area. ${ }^{20}$

We cannot exclude a placebo effect, since eliciting ('drumming up') attention around MVA may have influenced the health personnel irrespective of the training programme. Still, this may be regarded as a part of intervention, since we cannot clearly distinguish between reminder and factual refresher effects. Additionally, the post-intervention data were collected from 9 to 12 months after the training to rule out a potential placebo (Hawthorne) effect. Moreover, a separate training session was necessary at QECH due to the rotation schedule of the interns. Rotation of new inexperienced staff might have potentially led to a decline in the use of MVA, as was seen during the period between July and September
2016 (see table 2). Consequently, we may suggest that hospitals repeat the training for all staff each time new interns arrive or arrange refresher training sessions on a regular basis. This should be achievable as interns have compulsory educational sessions every week. We accept that rotation of staff undeniably is a problem in the implementation of research. Nevertheless, training can still be constructive if one manages to influence attitudes and skills among junior staff, who typically adopt procedures and protocols from their more experienced peers. Two annual training sessions would likely be adequate for both bigger and smaller hospitals.

So-called task shifting has proven to be beneficial in other jurisdictions ${ }^{23}$ and gives doctors more time for patients who urgently need their care. For instance, in Scandinavian countries, nurses and/or midwives can specialise in specific areas, such as routine obstetric ultrasound examination. ${ }^{24}$ In any healthcare system with a limited number of physicians, it may become necessary to trust and instil confidence in nurses to administer MVA as well as other technical skills. In fact, we have shown that task shifting seemed to have worked positively, particularly in the district hospitals with fewer doctors and clinical officers. In future interventions including regular updating of knowledge and skills, task shifting may constitute an important component.

The results from the district hospitals were not as successful as those observed at the QECH. Perhaps the former are more vulnerable when it comes to the supply of equipment and rotation of staff. Also, they have fewer doctors and supervisors. Nevertheless, a change in attitude in the central hospital can potentially have a robust delayed post-intervention effect as many of the interns eventually will work as district medical officers and leaders in the district hospitals. 
Another finding in our material was the large number of second trimester abortions. We had similar findings in previous studies in the same area. ${ }^{14}$ Considering that most miscarriages occur in the first trimester, ${ }^{25}$ this could be an indication that many of these abortions are induced. At the same time, it may indicate that women are late in seeking care for incomplete miscarriages. A public health campaign to seek medical care sooner would likely be beneficial. Yet, it might be difficult to conduct such a campaign considering the restrictive abortion law. However, the focus could be on miscarriages as the symptoms are the same.

Organising and conducting training sessions in order to increase the use of MVA is not new. In the International Federation of Gynaecology and Obstetrics (FIGO) Initiative for prevention of unsafe abortion from 2008, replacing the traditional use of sharp curettage with MVA to treat incomplete abortion was an established objective. ${ }^{26-28}$ Studies conducted in Pakistan, Bangladesh and Cameroon following that initiative have shown that training was an efficient way of increasing the use of MVA and reduce the use of sharp curettage. ${ }^{26-28}$ However, these efforts were large-scale interventions with substantial donations of equipment, which makes the recipient hospitals vulnerable when the donations fade away. Our study aimed to demonstrate what can be done on a small scale to increase the use of MVA in healthcare facilities through engagement of the current staff and the available resources and equipment. Interestingly, a recent study conducted in the Honduras did not have the expected increase in the use of MVA following donation of equipment subsequent to the FIGO Initiative. ${ }^{29}$ However, the training of trainers in the Honduran Initiative seemed to focus more on values than on the actual MVA procedure. Indeed, one of the reasons for the low use of MVA identified in that follow-up study was a lack of properly trained health personnel. ${ }^{29}$ This indicates that even though availability of good quality equipment obviously is an important factor, retraining is an essential element for the provision of post-abortion care interventions. Our study supports this finding.

\section{CONCLUSIONS}

In conclusion, we found that a basic training intervention was useful for improving post-abortion care in the low-income country Malawi. Such interventions are recommended as a part of ongoing training of health personnel to ensure sustainable development. Systematic and recurrent training is an efficient way for enhancing better treatment methods and is effective in improving post-abortion care.

Acknowledgements With thanks we acknowledge Evert Nieboer, Emeritus Professor, McMaster University (Hamilton, Ontario, Canada) for language editing. We also thank our colleagues at the College of Medicine in Blantyre, and the research assistants at Chiradzulu District Hospital, Chikwawa District Hospital and Queen Elizabeth Central Hospital who participated in the data collection and the intervention.
Contributors MLO and ED contributed to the study design. MLO, GM-G and ED developed and executed the training. MLO prepared and cleaned the data. MLO, GWJ and ED analysed the data. GWJ provided input to the statistical methods and interpretation of the results. MLO did the literature reviews. MLO, GM-G, UK, Jø0 and ED implemented the study. GM-G, UK, Jø0 and ED provided substantial comments to the draft. All authors contributed to the collection and the interpretation of data, provided critical revisions to the report and approved the final draft.

Funding Funding was provided by the Programme for Global Health and Vaccination Research (GLOBVAC), project number 244672, in conjunction with the Research Council of Norway.

Competing interests None declared.

Patient consent Not required.

Ethics approval Ethical approval was achieved from the Regional Committee for Medical and Health Research Ethics in Central Norway, reference 2015/455, and the College of Medicine Research Ethics Committee in Malawi, reference P.06/15/1748/

Provenance and peer review Not commissioned; externally peer reviewed.

Data sharing statement The dataset is available upon request.

Open access This is an open access article distributed in accordance with the Creative Commons Attribution Non Commercial (CC BY-NC 4.0) license, which permits others to distribute, remix, adapt, build upon this work non-commercially, and license their derivative works on different terms, provided the original work is properly cited, appropriate credit is given, any changes made indicated, and the use is non-commercial. See: http://creativecommons.org/licenses/by-nc/4.0/.

\section{REFERENCES}

1. The World Bank. 2017. http://databank.worldbank.org/data/Views/ Reports/ReportWidgetCustom.aspx?Report_Name=CountryProfile\& $\mathrm{Id}=\mathrm{b} 450 \mathrm{fd} 57$ \&tbar=y\&dd=y\&inf=n\&zm=n\&country=MWI (accessed 30 Aug 2017).

2. United Nations. Human Development Index and its components. 2015 http://hdr.undp.org/en/composite/HDI (accessed 12 Jun 2017).

3. World Health Organization World health organization world cooperation strategy, 2008-2013. http://www.who.int/countryfocus/ cooperation_strategy/ccs_mwi_en.pdf (accessed 22 Jan 2018).

4. World Health Organization. Global health observatory data repository. 2015 http://apps.who.int/gho/data/view.main.1390?lang= en (accessed 22 Jan 2018).

5. National Statistics Office. Malawi demographic and health survey 2015-2016. 2016 https://dhsprogram.com/pubs/pdf/FR319/FR319. pdf (accessed 13 Feb 2018).

6. World Health Organization. Maternal mortality. 2016 http://www.who. int/mediacentre/factsheets/fs348/en/ (accessed 19 Jun 2017).

7. Malawian Penal Code. Chapter 7. Laws of Malawi, 1930:01.

8. Geubbels E. Epidemiology of Maternal Mortality in Malawi. Malawi Med J 2006;18:206-25.

9. Lema VM, Changole J, Kanyighe C, et al. Maternal mortality at the Queen Elizabeth Central Teaching Hospital, Blantyre, Malawi. East Afr Med J 2005;82:3-9.

10. Polis $\mathrm{CB}$, Mhango $\mathrm{C}$, Philbin J, et al. Incidence of induced abortion in Malawi, 2015. PLoS One 2017;12:e0173639.

11. Malawi Government. The Law Commission Discussion Paper on Review of Abortion Law in Malawi, 2013.

12. Levandowski BA, Mhango $\mathrm{C}$, Kuchingale $\mathrm{E}$, et al. The incidence of induced abortion in Malawi. Int Perspect Sex Reprod Health 2013;39:088-96.

13. Kalilani-Phiri L, Gebreselassie H, Levandowski BA, et al. The severity of abortion complications in Malawi. Int J Gynaecol Obstet 2015;128:160-4.

14. Odland ML, Rasmussen H, Jacobsen GW, et al. Decrease in use of manual vacuum aspiration in postabortion care in Malawi: a crosssectional study from three public hospitals, 2008-2012. PLoS One 2014;9:e100728.

15. World Health Organization. Safe abortion: technical and policy guidance for health systems. 2012 http://apps.who.int/iris/bitstream/ 10665/70914/1/9789241548434_eng.pdf?ua=1 (accessed 1 Jun 2017).

16. The Association of Obstetricians \& Gynaecologists of Malawi. Obstetrics \& gynaecology protocols and guidelines. 2014. Version 1.0 ed.

17. Forna F, Gülmezoglu AM. Surgical procedures to evacuate incomplete abortion. Cochrane Database Syst Rev 2001;1:CD001993. 
18. Tunçalp O, Gülmezoglu AM, Souza JP. Surgical procedures for evacuating incomplete miscarriage. Cochrane Database Syst Rev 2010;9:CD001993.

19. Jejeebhoy SJ, Kalyanwala S, Zavier AJ, et al. Can nurses perform manual vacuum aspiration (MVA) as safely and effectively as physicians? Evidence from India. Contraception 2011;84:615-21.

20. Cook S, de Kok B, Odland ML. 'It's a very complicated issue here': understanding the limited and declining use of manual vacuum aspiration for postabortion care in Malawi: a qualitative study. Health Policy Plan 2017;32:305-13.

21. Metaferia AM, Muula AS. Stillbirths and hospital early neonatal deaths at queen elizabeth central hospital, blantyre-malawi. Int Arch Med 2009;2:25.

22. Ipas. Ipas. Performing Manual Vacuum Aspiration (MVA) Using the Ipas MVA Plus $®$, Ipas $3 \mathrm{~mm}$ and Ipas EasyGrip $®$ Cannulae. Chapel Hill, NC: IPAS Protecting women's health. (accessed 24 Aug 2018).

23. Bolkan HA, van Duinen A, Waalewijn B, et al. Safety, productivity and predicted contribution of a surgical task-sharing programme in Sierra Leone. Br J Surg 2017;104:1315-26.
24. Jansson C, Adolfsson A. A Swedish study of midwives' and nurses' experiences when women are diagnosed with a missed miscarriage during a routine ultrasound scan. Sex Reprod Healthc 2010;1:67-72.

25. The Johns Hopkins Manual of Gynecology and Obstetrics. 4 ed: Lippincott Williams and Wilkins, 2012:438-9.

26. Begum F, Zaidi S, Fatima $P$, et al. Improving manual vacuum aspiration service delivery, introducing misoprostol for cases of incomplete abortion, and strengthening postabortion contraception in Bangladesh. Int J Gynaecol Obstet 2014;126(Suppl 1):S31-S35.

27. Tumasang F, Leke RJ, Aguh V. Expanding the use of manual vacuum aspiration for incomplete abortion in selected health institutions in Yaoundé, Cameroon. Int J Gynaecol Obstet 2014;126(Suppl 1):S28-S30.

28. Zaidi S, Yasmin H, Hassan L, et al. Replacement of dilation and curettage/evacuation by manual vacuum aspiration and medical abortion, and the introduction of postabortion contraception in Pakistan. Int J Gynaecol Obstet 2014;126(Suppl 1):S40-S44.

29. Chinchilla AL, Flores IF, Morales AF, et al. Changes in the use of manual vacuum aspiration for postabortion care within the public healthcare service network in Honduras. Int J Gynaecol Obstet 2014;126(Suppl 1):S24-S27. 